\title{
Laparoscopic Resection of Renal Capsular Endometriosis in a Woman with Menstrual-Related Flank Pain: Case Report
}

\author{
Abbas Basiri, Iman Ghanaat and Hamidreza Akbari Gilani* (i)
}

\begin{abstract}
Background: Although involvement of the urinary system is not uncommon, endometriosis in the kidneys is rare. To date, laparoscopic partial nephrectomy has been the preferred approach for managing renal endometriosis. Here, we report for the first time the results of laparoscopic removal of a renal capsular endometriosis in a malrotated kidney in an attempt to save the whole kidney parenchyma, in terms of feasibility and safety.

Case presentation: A 37-year-old female presented with periodic right flank pain associated with her menstrual cycle. On imaging, a malrotated right kidney and a hypodense irregular-shaped lesion measuring $30 * 20 * 15 \mathrm{~mm}$ were seen in the superior portion of the right perinephric space. Histologic evaluation of the ultrasound-guided biopsy was consistent with renal capsular endometriosis. The patient underwent laparoscopic surgery to remove the capsular mass while preserving the normal renal parenchyma. Pathological examination of the biopsy obtained during surgery was in favor of renal endometriosis. At 6-month follow-up, the patient's pain had completely disappeared and no complications had occurred. In addition, imaging did not show any remarkable recurrence.
\end{abstract}

Conclusion: Renal endometriosis should be strongly considered as a differential diagnosis in female patients with a renal capsular mass and exacerbation of flank pain during menstruation. Based on our experience, with preoperative needle biopsy and clearing the pathology, laparoscopic removal of the mass in spite of renal anatomic abnormality is feasible and safe and thus could be considered as a possible treatment option.

Keywords: Endometriosis, Malrotated kidney, Laparoscopy, Renal capsule

\section{Background}

Endometriosis is characterized by the abnormal ectopic growth of endometrial tissue outside the uterus, most commonly in the pelvic cavity [1]. Extrapelvic sites such as the gastrointestinal tract and the urinary system might also be affected less frequently [2-4]. Signs and symptoms vary greatly depending on the site of involvement, but the association of symptoms with menstrual cycles raises the clinical suspicion of endometriosis. Although imaging aids in the initial diagnosis, the final diagnosis

\footnotetext{
*Correspondence: hamidrezaakbari1261@gmail.com

Departments of Kidney Transplantation and Urology, Shahid Labbafinejad

Medical Center, Urology and Nephrology Research Center, Tehran, No
}

103, 9th Boustan, Pastaran, Tehran 1666697751, Iran must be confirmed through histologic examination [5]. Since medical treatment is associated with recurrence of symptoms, surgery is the standard of choice for managing renal endometriosis, unless in special cases $[6,7]$.

Herein, we report a 37-year-old woman with right flank pain and a malrotated right kidney who was found to be a case of renal endometriosis following further evaluation. Although laparoscopic partial nephrectomy is the preferred treatment in this patient, we performed laparoscopic removal of the renal capsular endometriosis to preserve kidney function. This study aims to discuss the feasibility and complications of this treatment modality. 


\section{Case presentation}

In June 2019, a 37-year-old female was referred to our center with menstrual-related periodic right flank pain. She did not report any significant past medical or surgical history and was normal on physical examination. She had given birth to two children via normal delivery many years ago. Routine laboratory tests were normal. Ultrasonic assessment (US) showed mild hydronephrosis of the right kidney. Further evaluation with computed tomography (CT) revealed a malrotated right kidney with mild hydronephrosis, but no obstruction was seen on contrast-enhanced imaging. Moreover, a hypodense irregular-shaped lesion, probably originating from the renal capsule, was noted in the superior portion of the right perinephric space causing mild pressure effect on the right kidney. The size of the lesion measured approximately $30 * 20 * 15 \mathrm{~mm}$ (Figs. 1a, b and 2). In the next step, US-guided percutaneous renal mass biopsy was performed and histologic examination revealed loosing benign endometrial growth and fibroconnective stroma in favor of endometriosis. Following confirmation of the diagnosis, we decided to enucleate the renal capsular mass, laparoscopically.

After placing the patient in right flank position and inserting four trocars, the malrotated right kidney was exposed transperitoneally (Fig. 3). Subsequent to finding the exact site of the mass, laparoscopic enucleation and complete removal of the renal capsular mass were performed with the preservation of normal renal parenchyma. No significant bleeding occurred during this process, and the obtained specimen was eventually sent for pathologic evaluation (Fig. 4).

On pathological examination, a $60 * 25 * 10 \mathrm{~mm}$ mass (Fig. 5) containing fibroadipose tissue along with clusters of endometrial glands and stroma (endometrial nests) and hemorrhage was seen which was compatible with the diagnosis of renal capsular endometriosis (Figs. 6, 7).

At 6-month follow-up, the patient did not complain of any complications and her pain had completely disappeared. Also, imaging study at 4 months after surgery showed no remarkable recurrence of the mass (Fig. 8).

\section{Discussion}

Endometriosis or extra-uterine endometrial growth might occur in the urinary system, mainly affecting the bladder and ureters and rarely the kidneys. The median age of diagnosing extrapelvic endometriosis is 34-40 years [8]. The first published report of renal endometriosis dates back to the 1950 s in which metaplasia was thought to be the possible etiology [9-11].

Renal endometriosis might be associated with pain and hematuria $[13,14,17-19]$, or it could be symptomless

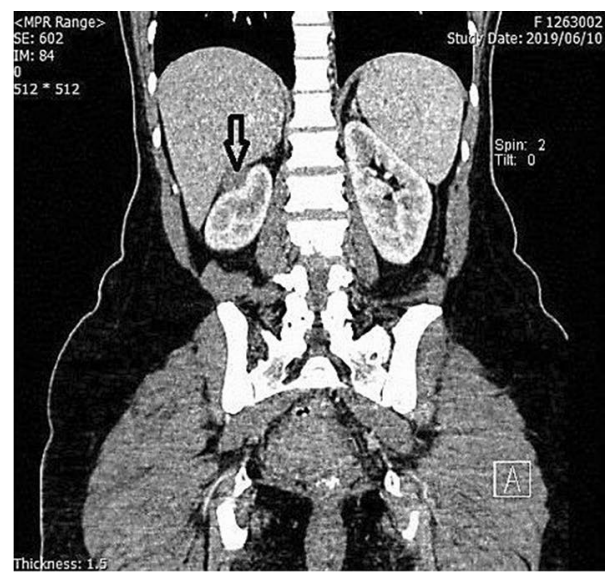

a

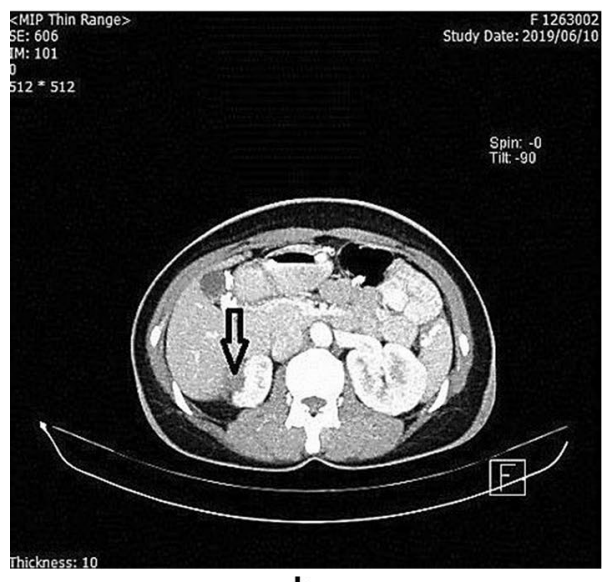

b

Fig. 1 a Abdominopelvic CT showing a heterogeneous mass (black arrow) with pressure effect on the upper pole of the right kidney (coronal view). b. Abdominopelvic CT showing a heterogeneous mass (black arrow) with pressure effect on the upper pole of the right kidney (axial view)

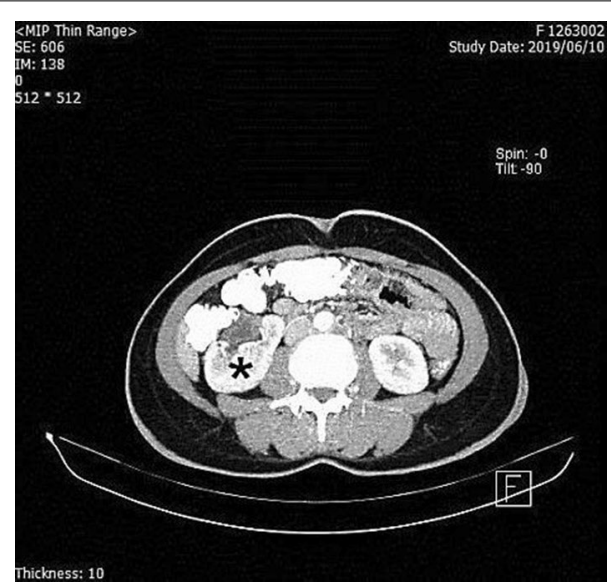

Fig. 2 Abdominopelvic CT showing malrotated right kidney (black star) and anteriorly oriented right renal pelvis 


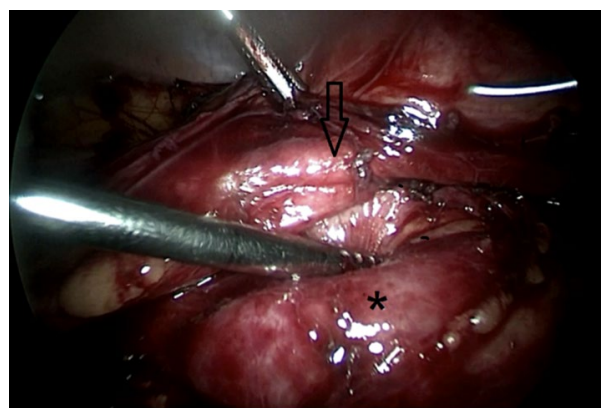

Fig. 3 Malrotated right kidney (black star). The arrow shows the anteriorly oriented renal pelvis and ureter

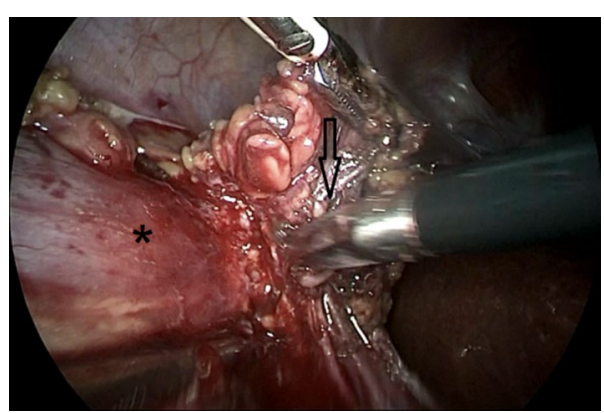

Fig. 4 Laparoscopic resection of the capsular mass with a safe margin. The black star shows normal renal parenchyma, and the arrow shows the mass being resected

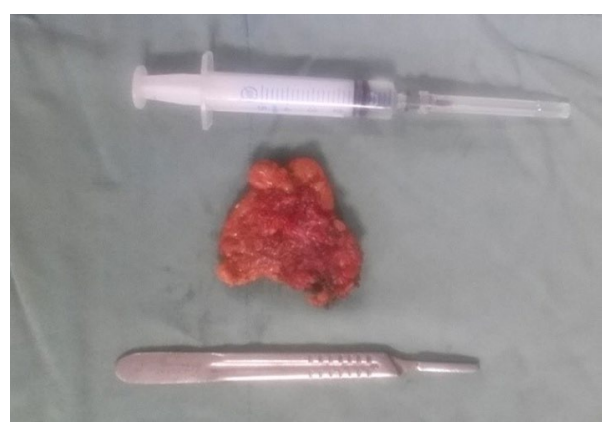

Fig. 5 Macroscopic (gross) view of the capsular mass

$[15,16]$. On imaging, it presents either as a mass [14-17], complicated cyst [15-18] or a subcapsular hematoma [19]. The case described here presented with a capsular mass without any abnormality in the renal parenchyma except for fat stranding around the mass in the perinephric space.

Regarding the surgical management of such patients, different approaches such as open, laparoscopic, and robotic-assisted partial nephrectomy have been utilized

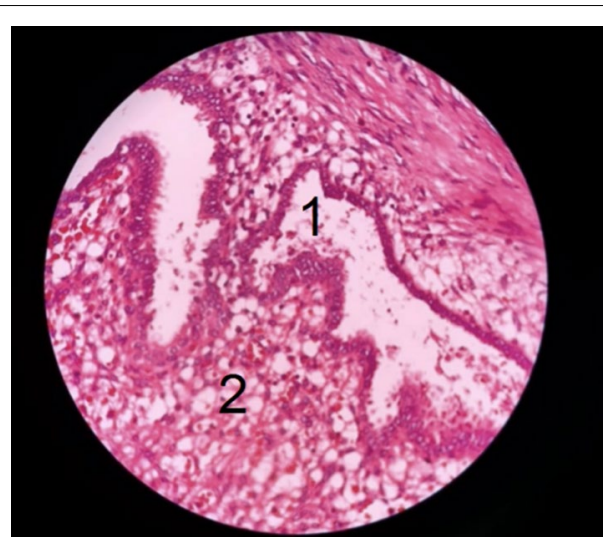

Fig. 6 Microscopic view of the specimen (Regions 1 and 2 show the endometrial nests and fibroadipose tissue of the renal capsule, respectively)

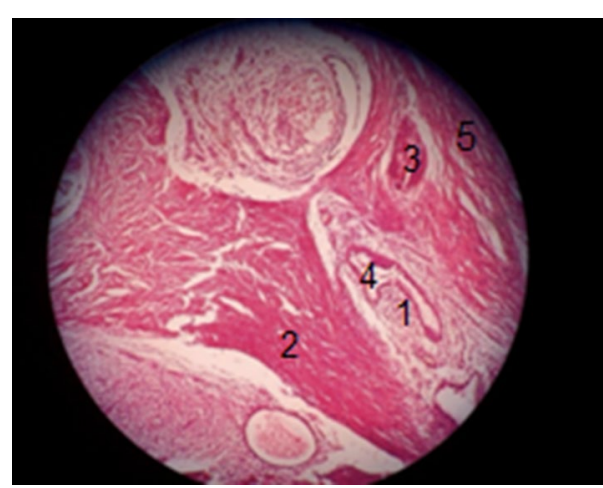

Fig. 7 Microscopic view of the specimen (Regions 1, 2, 3, 4, and 5 show fibroadipose tissue, stroma, hemorrhage, endometrial nest, and the renal capsule, respectively)

so far $[5,12,14,19]$. This is the first report of laparoscopic removal of a renal capsular endometriosis mass in an attempt to save the whole kidney.

Dirim et al. in Fertility and Sterility in 2009 reported a $15 \mathrm{~cm}$ left kidney subcapsular hematoma, which, after partial drainage by percutaneous catheter, was explored by open flank incision. The final pathology was renal capsular endometriosis [5].

Elham Arabzadeh et al. in American Journal of Clinical Pathology in 2018 reported laparoscopic partial nephrectomy of $3 \mathrm{~cm}$ enhancing left renal mass with preoperative suspicion of RCC. The final pathology was renal endometriosis. The authors concluded that in the appropriate clinical setting and suspicion of renal endometriosis, needle biopsy may prevent overtreatment and lead to preservation of renal normal parenchyma [12]. 

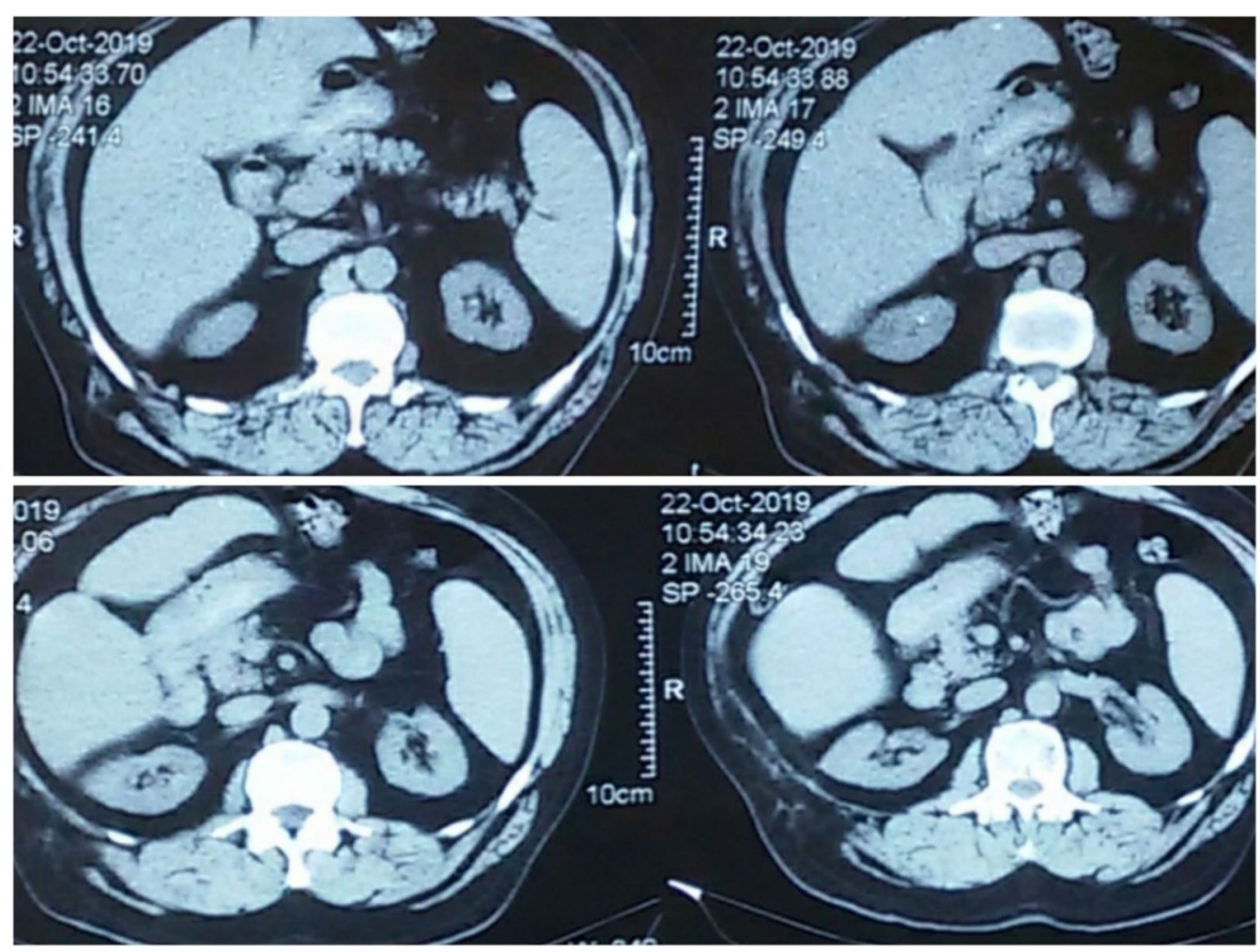

Fig. 8 Abdominopelvic CT at 4 months postoperative visit, showing no recurrence at the site of previous right renal capsular mass

Badri et al. in Journal of Endourology Case Report in 2018 reported robotic partial nephrectomy of $3 \mathrm{~cm}$ enhancing left renal mass, which postoperatively proved to be endometriosis [14].

Giambelluca et al. in Chir in 2017 reported two cases of incidentally found asymptomatic renal endometriosis, proved by needle biopsy. As in both patients, renal lesions were asymptomatic and unchanged on subsequent imaging examination, and no therapy was needed [15].

To the best of our knowledge, this is the first case report of renal endometriosis with menstrual-related pain, diagnosed preoperatively, with attempt to remove just the endometrial mass and save the whole kidney. Previous articles had considered open or laparoscopic partial nephrectomy, mainly because there was preoperative probability of malignancy. Performing fine needle aspiration or biopsy before definite intervention helps the physician to decide about the best choice of treatment by ruling out other differential diagnoses [20]. We performed US-guided biopsy for our patient before surgery which was consistent with renal capsular endometriosis. This provided us with a better outlook on the patient's nature of disease and allowed us to select a minimally invasive modality, confidently.
Nevertheless, this individual experience is not expandable to different types of renal capsular endometriosis or various renal anatomic abnormalities. Thus, a larger number of cases are required for better concluding results.

\section{Conclusion}

In this paper, we have reported for the first time the laparoscopic removal of a histologically documented isolated renal capsular endometriosis in a malrotated kidney. We considered saving the whole kidney, which was not associated with any early or late complications. Based on our experience in this patient, we recommend minimally invasive treatment modalities as a suitable option for renal endometriosis in the presence of renal anatomic abnormality. However, further experience of managing similar patients with this approach is warranted to reach a conclusion regarding its safety and feasibility.

\section{Abbreviations}

RCC: Renal cell carcinoma; CT: Computerized tomography.

\section{Acknowledgements}

We acknowledge the pathology ward of Labbafinejad medical center for their help and support in preparing this case report. 


\section{Authors' contributions}

$\mathrm{AB}$ has made substantial contribution in treatment plan and performance, editing the final and modified version of the manuscript. IG has made substantial contribution in treatment of the patient and writing of initial version of the manuscript. HAG has made substantial contribution in treatment plan and performance, editing the final and modified versions of the manuscript. All the authors have participated in patient treatment and writing the article. All authors read and approved the final manuscript.

\section{Funding}

Not applicable.

\section{Availability of data and materials}

Patient's medical files and operation video are available in Labbafinejad medical center.

\section{Declarations}

\section{Ethics approval and consent to participate}

The treatment procedure was according to ethical guidelines of our center. We obtained written informed consent for participation from the participant patient.

\section{Consent for publication}

Written Informed consent for publication of case report was obtained from the participant patient.

\section{Competing interests}

There was no funding for the study and no conflicts of interest to disclose.

Received: 13 February 2021 Accepted: 12 June 2021

Published online: 27 June 2021

\section{References}

1. Signorile PG, Baldi A (2010) Endometriosis: new concepts in the pathogenesis. Int J Biochem Cell Biol 42(6):778-780

2. Moore JG, Hibbard LT, Growdon WA, Schifrin BS (1979) Urinary tract endometriosis: enigmas in diagnosis and management. Am J Obstet Gynecol 134(2):162-172. https://doi.org/10.1016/0002-9378(79)90881-0

3. Comiter CV (2002) Endometriosis of the urinary tract. Urol Clin North Am 29(3):625-635. https://doi.org/10.1016/s0094-0143(02)00065-4

4. Razzaghi MR, Rahjoo T, Golshan A et al (2009) Endometriosis with pure urinary symptoms. Urol J 6(2):132-134

5. Dirim A, Celikkaya S, Aygun C, Caylak B (2009) Renal endometriosis presenting with a giant subcapsular hematoma: case report. Fertil Steril 92(1):391-391. https://doi.org/10.1016/j.fertnstert.2009.04.013

6. Somigliana E, Busnelli A, Benglia L et al (2017) Postoperative hormonal therapy after surgical excision of deep endometriosis. Eur J Obst Gynecol Reprod Biol 209:77-80. https://doi.org/10.1016/j.ejogrb.2016.03.030
7. Nezhat C, Falik R, McKinney S, King LP (2017) Pathophysiology and management of urinary tract endometriosis. Nat Rev Urol 14(6):359-372. https://doi.org/10.1038/nrurol.2017.58

8. Singh KK, Lessells AM, Adam DJ et al (1995) Presentation of endometriosis to general surgeons: a 10-year experience. Br J Surg 82(10):1349-1351. https://doi.org/10.1002/bjs.1800821017

9. Blum E, Fruhling L (1953) Renal endometriosis, a new anatomic-clinical entity; symptoms and pathogensis; with reference to two personal cases. J Chir (Paris) 69(1):19-37

10. Fruhling L, Hurter E, Blum E (1952) New observations of renal endometriosis; metaplasy of renal parenchyma. Gynecol Obstet (Paris) 51(3):271-275

11. Fruhling L, Blum E (1951) Renal endometriosis; metaplastic origin of endometriosis. J Urol Medicale Chir 57(3-4):151-162

12. Arabzadeh E, Schneider C, Mukherjee A (2018) Renal endometriosis: an unusual presentation of a common disease. Am J Clin Pathol 150:S1-S55. https://doi.org/10.1093/AJCP/AQY090

13. Cheng $\mathrm{CH}$, Kuo HC, Su B (2015) Endometriosis in a kidney with focal xanthogranulomatous pyelonephritis and a perinephric abscess. BMC Res Notes 21(8):591. https://doi.org/10.1186/s13104-015-1574-1

14. Badri AV, Jennings R, Patel P, Eun DD (2018) Renal endometriosis: the case of an endometrial implant mimicking a renal mass. J Endourol Case Rep 4(1):176-178. https://doi.org/10.1089/cren.2018.0070.eCollection2018

15. Giambelluca D, Albano D, Giambelluca E, Bruno A, Panzuto F, Agrusa A, Di Buono G, Cannizzaro F, Gagliardo C, Midiri M, Lagalla R, Salvaggio G (2017) Renal endometriosis mimicking complicated cysts of kidney: report of two cases. G Chir 38(5):250-255

16. Quimbayo-Arcila C, Moreno-Torres B, López-Guerrero M, Orradre-Romeo $\mathrm{J}$ (2019) Intratumoral endometriosis in renal angiomyolipomas associated to medium vessel necrotizing vasculitis in a patient with Wünderlich syndrome. A rare finding. Rev Esp Patol 52(3):202-204. https://doi.org/10. 1016/j.patol.2018.09.002

17. Tabakin AL, Dutton JL, Fatima A, Sadimin E, Jang TL (2018) Polypoid endometriosis presenting as a renal cortical tumor. Urology 119:e5-e7. https:// doi.org/10.1016/j.urology.2018.06.010

18. Yaqub U, Hassan SE, Yusaf Z, Yusuf AW (2008) Endometriosis in the renal area. J Coll Phys Surg Pak 18(3):174-175

19. Dirim A, Celikkaya S, Aygun C, Caylak B (2009) Renal endometriosis presenting with a giant subcapsular hematoma: case report. Fertil Steril 92(1):391.e5-391.e7

20. Gupta K, Rajwanshi A (2005) Srinivasan REndometriosis of the kidney: diagnosis by fine-needle aspiration cytology. Diagn Cytopathol 33(1):60-61

\section{Publisher's Note}

Springer Nature remains neutral with regard to jurisdictional claims in published maps and institutional affiliations.

\section{Submit your manuscript to a SpringerOpen ${ }^{\circ}$ journal and benefit from:}

- Convenient online submission

- Rigorous peer review

- Open access: articles freely available online

- High visibility within the field

Retaining the copyright to your article

Submit your next manuscript at springeropen.com 